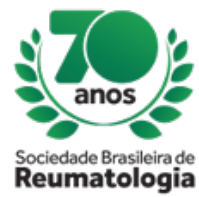

\title{
CHRONIC CARDIOPATHY SECONDARY TO RHEUMATIC FEVER: A SERIOUS PUBLIC HEALTH PROBLEM IN BRAZIL AN EVALUATION OF HOSPITALIZATIONS AND MORTALITY FROM 2008-2018
}

Mariana Silva Nunes (Faculdade de Medicina - Centro Universitário de Brasília, Brasília, DF, Brasil), Gustavo Tedde Filho (Faculdade de Medicina - Centro Universitário de Brasília, Brasília, DF, Brasil), João Carlos Geber Júnior (Departamento de Clínica Médica - Hospital Alvorada Brasília, Brasília, DF, Brasil), Viviane Cristina Uliana Peterle (Faculdade de Medicina - Escola Superior de Ciências da Saúde, Brasília, DF, Brasil), Ana Paula Monteiro Gomides Reis (Faculdade de Medicina - Centro Universitário de Brasília, Brasília, DF, Brasil)

\section{BACKGROUND}

Rheumatic fever (RF) is a systemic inflammatory disease caused by group A beta-hemolytic streptococcus. Its main complication is chronic cardiopathy (mitral and aortic valvulitis), with high rates of sequelae and mortality. FR is one of the main causes of severe cardiopathy in young adults and its complications are responsible for a high percentage of cardiac surgeries in Brazil, causing great impact on individual and public health.

\section{MATERIALS AND METHODS}

Descriptive, ecological study, in a time series, based on data obtained from the Hospital Information System of the Unified Health System (SIH-SUS). Data on chronic rheumatic heart disease (ICD-10 I05-I09 codes) were collected from patients between 1 and 79 years of age in the period 2008-2018. The analyzed variables were number of hospitalizations, total value and mean value by hospitalization, mean hospital stay, deaths and mortality rate.

\section{RESULTS}

The total number of hospitalizations in the period was 83,209 , of which 48,232 were female and 35,577 were male. In relation to the regions of Brazil the southeastern region had the highest number of hospitalizations (Table 1). The distribution of the number of hospitalizations, deaths and mortality rate by age group can be seen in table 2 . The total amount spent in hospitalizations in this period was $R$ $879,676,458.63$, with an average hospitalization value of $R \$ 10,496.21$. The mean length of hospital stay was 12.7 days.

\section{CONCLUSION}

$\mathrm{RF}$ is a common disease in Brazil. Despite probable underreporting, hospitalizations for chronic cardiac complications recorded in the official database demonstrated important data such as the high cost of hospitalization and the number of deaths. Studies with this should serve as an alert regarding the importance of early diagnosis and treatment of RF in our country. 